\title{
Triptolide induces cell apoptosis in human stomach cancer cell via caspase 3-dependent cascade pathway
}

\author{
Shuai Liu ${ }^{1,2}$, Jing Zhang ${ }^{3}$, Xiao-Zhan Zhang ${ }^{1}$, Hui-Hui Zhang ${ }^{1},{\text { Xing-Wu } \text { Li }^{1} \text { and }}^{1}$ \\ Shi-Jie Zhang ${ }^{1 *}$ \\ ${ }^{1}$ Department of Clinical Laboratory, The First Affiliated Hospital of Zhengzhou University, ${ }^{2}$ Key Laboratory of Clinical Laboratory \\ Medicine of Henan Province, ${ }^{3}$ Zhengzhou Traditional Chinese Medical Hospital, Zhengzhou, China
}

*For correspondence: Email: zhangshijie2001@126.com; Tel: +86-371-66295013

\begin{abstract}
Purpose: To evaluate the effect of triptolide on the induction of cell apoptosis in human gastric cancer BGC-823 cells.

Methods: The cytotoxicity of triptolide was evaluated by 3-(4, 5-dimethylthiazol-2-yl)-2, 5diphenyltetrazolium bromide (MTT) assay. The effect of triptolide on cell proliferation was measured using lactate dehydrogenase (LDH) assay. Cell apoptosis was determined by Annexin V/propidium iodide (PI) double-staining assay.

Results: MTT results indicate that triptolide significantly decreased cancer cell numbers in dose- and time-dependent manners in MTT assay. Data from LDH assay showed that triptolide markedly induced cytotoxicity in gastric cancer cells. Triptolide also remarkably induced both early and late apoptotic process in BGC-823 cells. In addition, the compound down-regulated the expression of anti-apoptotic Bcell lymphoma-2 (bcl-2) and up-regulated the expression of pro-apoptotic BCL-2-associated X (bax) in a dose-dependent manner. Furthermore, the pro-apoptotic activity of triptolide was involved in the activation of caspase-3 pathway in BGC-823 cells.

Conclusion: Taken together, the findings strongly indicates that the pro-apoptotic activity of triptolide is regulated by caspase 3-dependent cascade pathway, and thus needs to be further developed for cancer therapy.
\end{abstract}

Keywords: Triptolide, Gastric cancer therapy, Apoptosis, Cytotoxicity, Caspase

\begin{abstract}
Tropical Journal of Pharmaceutical Research is indexed by Science Citation Index (SciSearch), Scopus, International Pharmaceutical Abstract, Chemical Abstracts, Embase, Index Copernicus, EBSCO, African Index Medicus, JournalSeek, Journal Citation Reports/Science Edition, Directory of Open Access Journals (DOAJ), African Journal Online, Bioline International, Open-J-Gate and Pharmacy Abstracts
\end{abstract}

\section{INTRODUCTION}

Gastric cancer is now ranking the second leading cause of cancer-related deaths worldwide [1]. Surgery combined with chemotherapy is the current option for most patients diagnosed with advanced gastric cancer [2]. Due to the high rates of side effects and rapid therapeutic resistance, the efficacy of traditional chemotherapeutic drugs in the cancer treatment has declined [3]. Therefore, it is necessary and urgent to develop novel therapeutic agents which have higher efficacy but with limited side effects and low resistance.

Emerging evidences have shown that natural compounds from medicinal plants exhibit promising results in controlling various diseases, including cancers [4,5]. The root of Trypterigium wilfordii Hook L, also known as "Thunder of God Vine" is one traditional Chinese medicine that has been reported to have diverse biological activities including anti-arthritis, anti-Alzheimer and anti-cancer effects [6-8]. Triptolide is one of 
the active diterpene triepoxide compound identified from Trypterigium wilfordii Hook L. To date, triptolide has been found to exert potent immunosuppressive and anti-inflammatory properties [9]. Triptolide is also demonstrated to have anti-cancer effects in several cancer types including lung cancer [10], liver cancer [11], pancreatic cancer [12], and colon cancer [13]. In addition, triptolide is also able to cause pancreatic cancer cell death through induction of apoptosis via inhibition of HSP70 [12]. Triptolide has also been demonstrated to abrogate cell growth of colon cancer and induce cell cycle arrest through inhibiting transcriptional activation of E2F [14]. A recent study also suggests that the induction of cell death by triptolide is modified by autophagy in cardiomyocytes [15].

In order to extend the usage of triptolide for cancer treatment, we will evaluate the potent cytotoxic effects of triptolide in human gastric BGC-823 cells, and also explore the possible underlying mechanisms of this action in the current study.

\section{EXPERIMENTAL}

\section{Chemicals and reagents}

Triptolide, 3-(4,5-dimethylthiazol-2-yl)-2,5diphenyltetrazolium bromide (MTT), dimethyl sulfoxide (DMSO), and propidium iodide (PI) were purchased from Sigma Chemical Co. (St. Louis, MO, USA). All other reagents, supplements for cell culture and assay kits were obtained from Life Technologies (NY, USA), otherwise stated.

\section{Cell culture}

BGC-823 human gastric cancer cells were purchased from the Cell Storehouse of the Chinese Academy of Science (Shanghai, China). The cells were maintained in DMEM medium supplemented with $10 \% \mathrm{FBS}$ and $1 \% \mathrm{PS}$, and incubated in a humidified incubator at $37{ }^{\circ} \mathrm{C}$ with $5 \% \mathrm{CO}_{2}$.

\section{Cell viability assay}

In order to investigate the anti-cancer actions of triptolide, MTT assay was performed in BGC823 gastric cancer cells. The cells at a density of $5 \times$ $10^{4}$ cells/mL were seeded in 96-well plates and treated with various concentrations of triptolide $(10,20$, and $40 \mathrm{nM})$ or vehicle solution $(0.1 \%$ DMSO) for 48 or $72 \mathrm{~h}$. Then, $20 \mu \mathrm{L}$ of MTT (5 $\mathrm{mg} / \mathrm{mL}$ ) solution was added into each well and incubated for another $4 \mathrm{~h}$. After replacing the culture medium with $100 \mu \mathrm{L}$ of DMSO, the optical density (OD) was collected at the wavelength of $540 \mathrm{~nm}$ using a microplate reader (TECAN, Austria).

\section{LDH leakage assay}

Cell cytotoxicity was tested by LDH leakage assay according to the manufacturer's instructions. Briefly, after triptolide treatments, cell-free supernatants $(50 \mu \mathrm{L})$ were collected from each well and transferred into a new 96-well plate, and gently mixed with $50 \mu \mathrm{L}$ of CytoTox $96 \circledR$ non-radioactive cytotoxicity assay reagents. The plate was kept in the dark at room temperature for $30 \mathrm{~min}$. Stop solution $(50 \mu \mathrm{L}$ of each well) was added into the wells, before the OD value was examined at $492 \mathrm{~nm}$ using a microplate reader (TECAN, Austria).

\section{Annexin V/PI double-staining assay}

Annexin V/PI double-staining assay and flow cytometry (FACSalibur, BD) were performed to quantify the apoptotic cells after triptolide treatment. In brief, BGC-823 cells were seeded in 6-well plates at a density of $1 \times 10^{5}$ cells $/ \mathrm{mL}$ and treated with different concentrations of triptolide or DMSO for 48 or $72 \mathrm{~h}$. The cells were then harvested, rinsed twice with PBS, resuspended in binding buffer and incubated with fluorescein isothiocyanate (FITC)-conjugated Annexin $\mathrm{V}(5 \mu \mathrm{L})$ and $\mathrm{PI}(5 \mu \mathrm{L})$ in the dark for 15 min at room temperature. Then, the cells were washed with PBS twice, before subjecting to flow cytometry for data collection.

\section{Quantitative real-time polymerase chain reaction (q-PCR)}

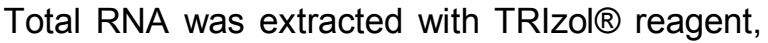
according to the manufacturer's instructions. One microgram of RNA from each sample was used for the reverse transcription reaction using Oligo dT (18T) (Omega, NY, USA). The cDNA products were amplified for bcl-2, bax, and gapdh gene expression via qRT-PCR using specific primers. PCR was performed with SYBR Green PCR Master Mix using a 7900HT qPCR system thermal cycler (Applied Biosystems, CA). The $C t$ values for each sample were normalized to GAPDH mRNA, which was used as an internal control. Data from three independent experiments were collected and calculated.

The primers used for q-PCR were: bax, forward (5'-TGGAGCTGCAGAGGATGATTG-3') and reverse (5'-GAAGTTGCCGTCAGAAAACATG3'); bcl-2, forward (5'-CTGCACCTGACGCCCTT CACC-3') and reverse (5'-CACATGACCCCACC 
GAACTCAAAGA-3'); GAPDH, forward (5'AACGGGAAGCTTGTCATCAATGGAAA-3') and reverse (5'-GCATCAGCAGAGGGGGCAGAG-3')

\section{Assessment of caspase-3 activity}

After treatment with triptolide, caspase- 3 activity was assessed using a commercial colorimetric activity assay kit (Beyotime, China), according to the manufacturer's instruction.

\section{Statistical analysis}

Data are expressed as mean \pm standard deviation (SD, $n=3)$. One-way ANOVA analysis was performed for statistical analysis using GraphPad Prism software, version 6.0. In all comparisons, $p<0.05$ was considered statistically significant.

\section{RESULTS}

Triptolide decreased cell proliferation in human gastric cancer BGC-823 cells

As shown in Figure 1, treatment with triptolide

A

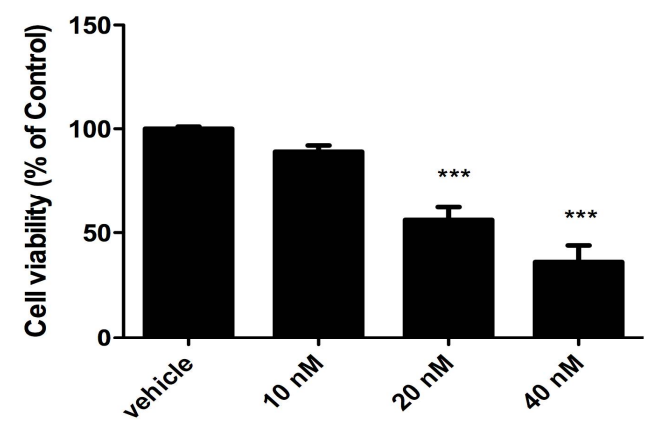

(10, 20 and $40 \mathrm{nM})$ significantly decreased cell proliferation and cell viability in both time- and concentration-dependent manner. Cell viability of BGC-823 cells were inhibited by 44 and $64 \%$ with triptolide treatment of 20 and $40 \mathrm{nM}$, respectively, for $48 \mathrm{~h}$, and 51 and $69 \%$ respectively for $72 \mathrm{~h}$.

\section{Triptolide induced cell cytotoxicity in human} gastric cancer BGC-823 cells

The cytotoxicity was examined by LDH leakage assay. Our results showed that toxic effects were increased in BGC-823 cells by triptolide treatment $(10,20$, and $40 \mathrm{nM})$ in a dosedependent manner (Figure 2).

\section{Triptolide induced cell apoptosis in human gastric cancer BGC-823 cells}

Cell apoptosis was measured by Annexin $\mathrm{V}$ and PI double-staining assays using flow cytometry. As shown in Figure 3, the total apoptotic cells were increased 10.3 and $42.6 \%$ by challenging

\section{B}

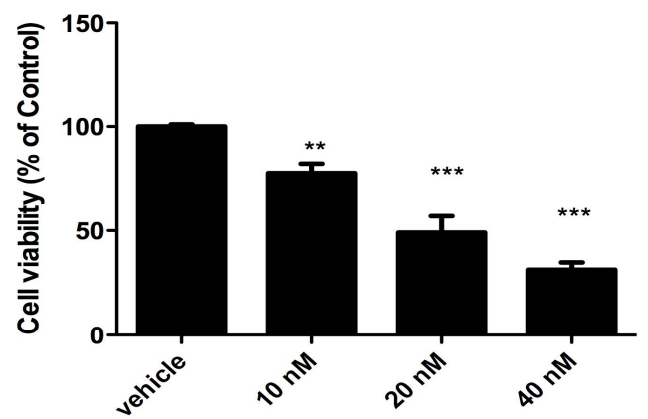

Figure 1: Cell viability of BGC-823 cells treated with triptolide. BGC-823 cells were treated with triptolide $(10,20$ and $40 \mathrm{nM}$ ) for $48 \mathrm{~h}(\mathrm{~A})$ or $72 \mathrm{~h}(\mathrm{~B})$. Data were expressed from three different experiments; ${ }^{* *} p<0.01,{ }^{* * *} p<$ 0.001 compared to vehicle control

A

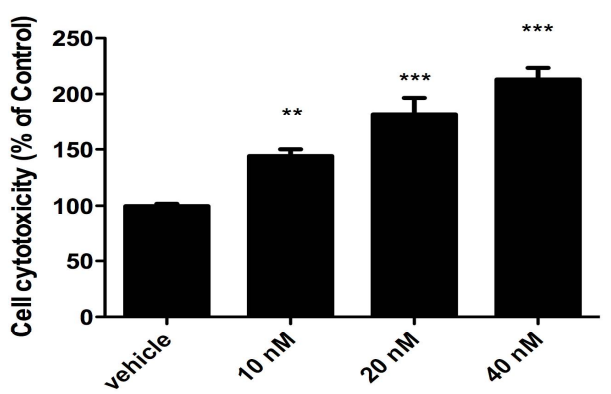

B

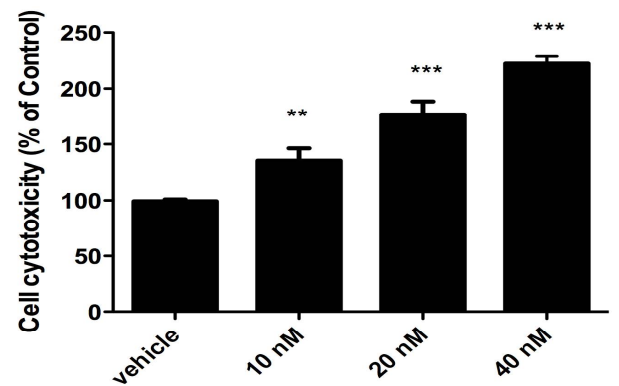

Figure 2: Cell cytotoxicity of BGC-823 cells treated with triptolide. BGC-823 cells were treated with triptolide (10, 20 and $40 \mathrm{nM}$ ) for $48 \mathrm{~h}(\mathrm{~A})$ or $72 \mathrm{~h}(\mathrm{~B})$. Data were expressed from three different experiments; ${ }^{* *} p<0.01$, ${ }^{* * *} p<$ 0.001 compared to vehicle control 
with $20 \mathrm{nM}$ and $40 \mathrm{nM}$ of triptolide for $48 \mathrm{~h}$ (Figure 3A), 14.5 and $48.3 \%$ for $72 \mathrm{~h}$ (Figure $3 B)$, respectively. These results suggested triptolide significantly increased both early apoptosis and late apoptosis in a dose-and timedependent manner.

Triptolide modulated the expression of apoptosis-related genes

In order to study the underlying mechanisms for triptolide-induced apoptosis, apoptosis related genes including $\mathrm{Bax}$ and $\mathrm{Bcl}-2$ mRNA were quantified by qPCR. As shown in Figure 4, the expression of Bax mRNA was markedly upregulated by triptolide treatment $(20$ and $40 \mathrm{nM})$ for 48 and $72 \mathrm{~h}$, with over-expression of $50-110$ $\%$. However, the expression of Bcl-2 mRNA was significantly inhibited by triptolide $(40 \mathrm{nM})$ for both $48 \mathrm{~h}$ and $72 \mathrm{~h}$, with inhibitory rate of over 50 $\%$.
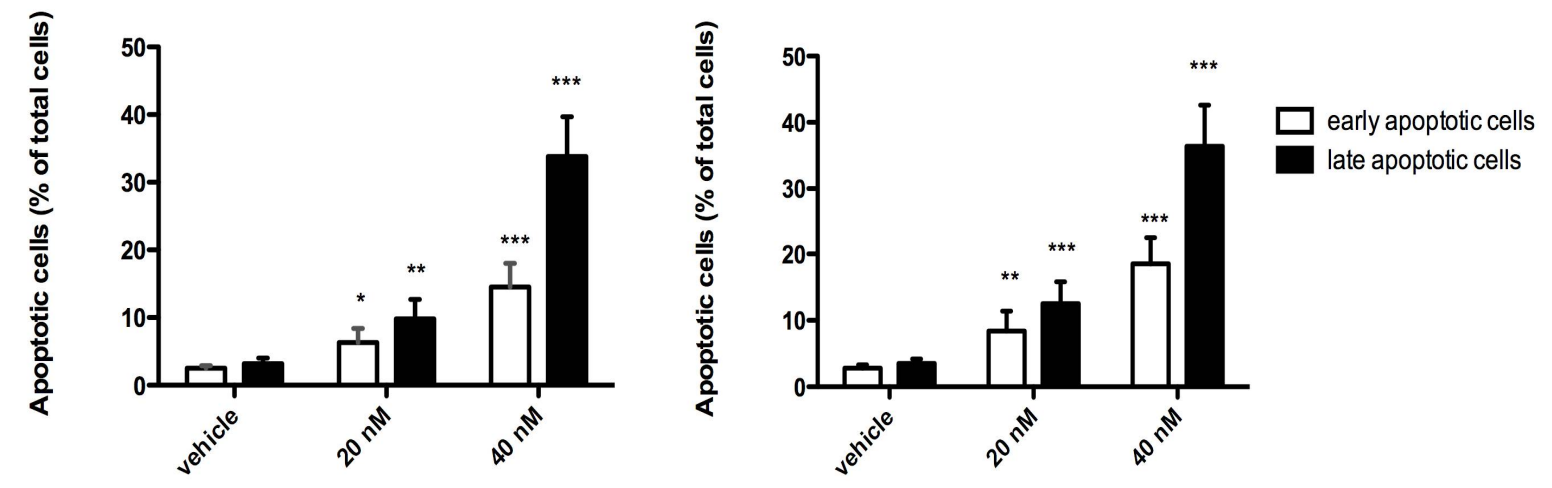

Triptolide activated caspase-3 activity in human gastric cancer BGC-823 cells

To confirm the involvement of caspase- 3 in triptolide-induced cell apoptosis, caspase-3 activity was measured by colorimetric activity assay. The results showed that caspase- 3 activity was increased by 5.3, 7.4 and 10.2 times by treatment with 10,20 and $40 \mathrm{nM}$ of triptolide in BGC-823 cells for $72 \mathrm{~h}$ (Figure 5A). The activation of caspase-3 activity was also increased by triptolide $(40 \mathrm{nM})$ in a timedependent manner (Figure 5B).

\section{DISCUSSION}

Triptolide is one of the active ingredients of Tripterygium wilfordii, which possesses a broad spectrum of biological activities such as antiinflammatory, anti-neoplastic and anti-cancer effects [15]. Triptolide exerts potent anti-cancer effects in several cancer types including lung

Figure 3: Cell apoptosis of BGC-823 cells treated with triptolide. BGC-823 cells were treated with triptolide (20 and $40 \mathrm{nM}$ ) for $48 \mathrm{~h}(\mathrm{~A})$ or $72 \mathrm{~h}(\mathrm{~B})$. Data were expressed from three different experiments; ${ }^{*} p<0.05$, ${ }^{* *} p<$ $0.01,{ }^{* *} p<0.001$ compared to vehicle control

A

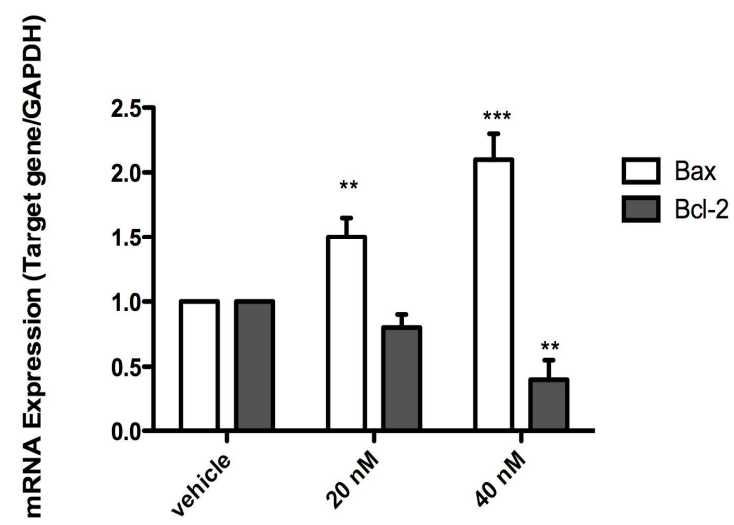

Figure 4: Apoptosis-related genes expression of BGC-823 cells treated with triptolide. BGC-823 cells were treated with triptolide $(20$ and $40 \mathrm{nM})$ for $48 \mathrm{~h}(\mathrm{~A})$ or $72 \mathrm{~h}(\mathrm{~B})$. Data were expressed from three different experiments; ${ }^{* *} p<0.01,{ }^{* * *} p<0.001$ compared to vehicle control
B

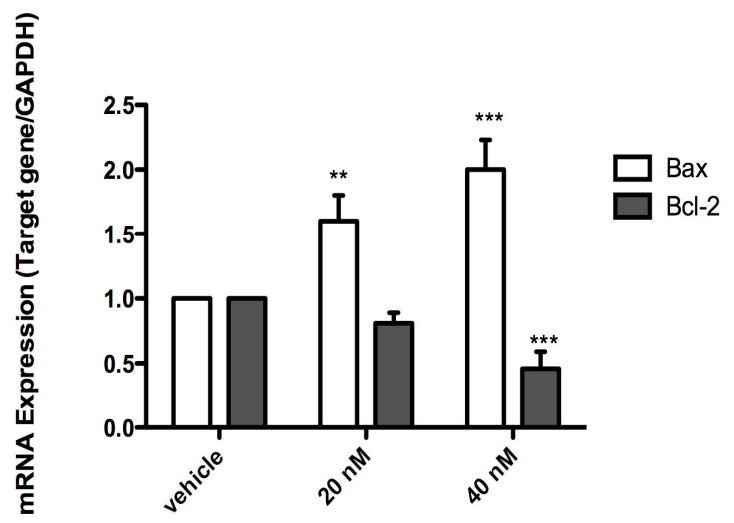


A

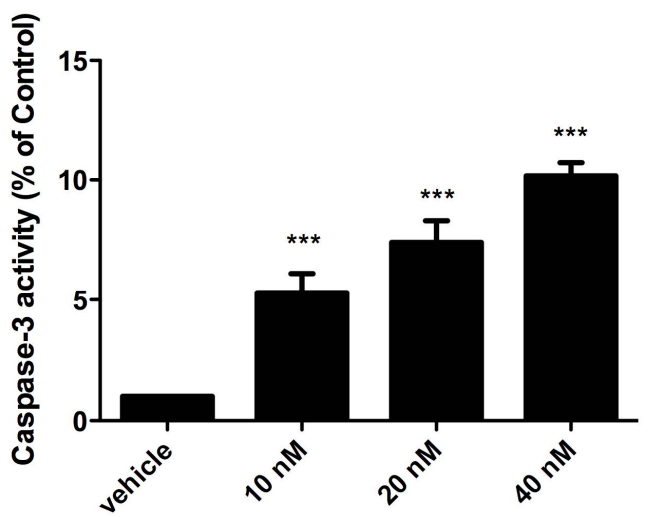

B

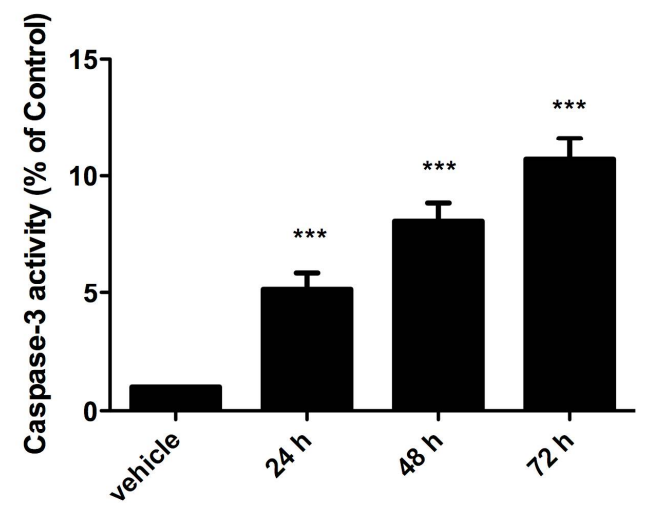

Figure 5: Caspase-3 activity of BGC-823 cells treated with triptolide. BGC-823 cells were treated with triptolide $(10,20$ and $40 \mathrm{nM})$ for $48 \mathrm{~h}(\mathrm{~A})$. BGC-823 cells were treated with $40 \mathrm{nM}$ of triptolide for 24,48 or $72 \mathrm{~h}$ (B). Data were expressed from three different experiments. ${ }^{* * *} p<0.001$ compared to vehicle control

cancer [10], liver cancer [11], pancreatic cancer [12], and colon cancer [13]. In our present study, we demonstrated that triptolide exhibited promising anti-cancer potential in human gastric BGC-823 cells. In addition, we also elucidated that the anti-cancer action of triptolide might be due to the induction of cell apoptosis in gastric cancer and the involvement of activation of caspase-3 pathway.

In our study, we used different method to evaluate the effects of triptolide in gastric BGC823 cells including MTT, LDH leakage, Annexin $\mathrm{V}$ and $\mathrm{PI}$ double staining assays. The MTT assay can detect both normal cells and necrotic cells. Therefore, we further used LDH leakage assay to detect the cytotoxic effects of triptolide in BGC cells. In order to confirm the pro-apoptotic effects induced by triptolide, we performed flow cytometry with Annexin V and PI double staining. Our results showed that triptolide significantly increased $\mathrm{LDH}$ in the cultured medium and increased apoptotic cells in flow cytometric analysis, which strongly suggested that triptolide was able to induce both cytotoxic and proapoptotic effects in human gastric BGC-823 cells.

Cancer is fundamentally a disease of dysregulation of tissue growth, in which programmed cell death is interfered with and blocked by tissue microenvironment. Apoptosis is the main form of programmed cell death that maintains tissue and cell hemostasis [16]. During the development of apoptosis, both anti-apoptotic proteins such as Bcl2 and pro-apoptotic proteins such as Bax are involved in the initiation and modulation of the process of apoptosis [17]. The expression of $\mathrm{Bcl} 2$, Bax or the ratio of $\mathrm{Bcl} 2$ and Bax are normally used as index of apoptosis [18]. In our current study, we observed that triptolide induced a remarkable up-regulation of Bax mRNA and a significant decrease of Bcl2 mRNA, which consequently lead to an increase of the $\mathrm{Bax} / \mathrm{Bcl} 2$ ratio.

These results indicate that triptolide-induced apoptosis employs both anti-apoptotic and proapoptotic proteins. The mitochondrial apoptotic pathway includes two alternate pathways, typically caspase- 8 and caspase- 9 . Caspase- 3 is a downstream molecule in caspase- 9 pathway [19]. In our study, treatment with triptolide significantly stimulated the activation of caspase3 , suggesting that a caspase-9 pathway may be involved in the triptolide-induced cell apoptosis in gastric cancer.

\section{CONCLUSION}

Treatment with triptolide remarkably induces both early and late apoptotic process. Triptolide also down-regulates the expression of anti-apoptotic B-cell lymphoma-2 (bcl-2) and up regulates the expression of pro-apoptotic BCL-2-associated $X$ (bax) in a dose-dependent manner. This process is accompanied by activation of caspase- 3 in BGC-823 cells using caspase-3 activity assay. Thus, these findings indicate that the apoptotic activity of triptolide is probably regulated by caspase-3-dependent cascade way. The demonstrated pro-apoptotic effects of triptolide will shed some light on application of this drug in cancer treatment especially in gastric cancer. 


\section{DECLARATIONS}

\section{Acknowledgement}

This study was financially supported by Education Department of Henan Province Science and Technology Research Projects (no. 14A320026), and Medical Science and Technology Project of Henan Province (no. 201503029).

\section{Conflict of Interest}

No conflict of interest associated with this work.

\section{Contribution of Authors}

The authors declare that this work was done by the authors named in this article and all liabilities pertaining to claims relating to the content of this article will be borne by them.

\section{REFERENCES}

1. Hou YC, Deng JY. Role of E3 ubiquitin ligases in gastric cancer, World J Gastroenterol 2015; 21: 786-793.

2. Wagner $A D$, Moehler M. Development of targeted therapies in advanced gastric cancer: promising exploratory steps in a new era, Curr Opin Oncol 2009; 21: 381-385.

3. Thiel A, Ristimaki A. Targeted therapy in gastric cancer. APMIS 2015; 123: 365-372.

4. Lee HW, Jang KS, Choi HJ, Jo A, Cheong JH, Chun KH. Celastrol inhibits gastric cancer growth by induction of apoptosis and autophagy, BMB Rep 2014; 47: 697-702.

5. Ji YB, Chen, N, Zhu HW, Ling N, Li WL, Song DX, et al. Alkaloids from beach spider lily (Hymenocallis littoralis) induce apoptosis of HepG-2 cells by the fas-signaling pathway, Asian Pac J Cancer Prev 2014; 15: 93199325.

6. Allison AC, Cacabelos R, Lombardi VR, Alvarez XA, Vigo C. Celastrol, a potent antioxidant and anti-inflammatory drug, as a possible treatment for Alzheimer's disease, Prog Neuropsychopharmacol Biol Psychiatry 2001; 25 : 1341-1357.

7. Ushiro S, Ono M, Nakayama J, Fujiwara T, Komatsu $Y$, Sugimachi $K$, et al. New nortriterpenoid isolated from anti-rheumatoid arthritic plant, Tripterygium wilfordii, modulates tumor growth and neovascularization, Int $\mathrm{J}$ Cancer 1997; 72: 657-663.
8. Wong KF, Yuan Y, Luk JM. Tripterygium wilfordii bioactive compounds as anticancer and antiinflammatory agents, Clin Exp Pharmacol Physiol 2012; 39: 311-320.

9. Yang F, Bai XJ, Hu D, Li ZF, Liu KJ. Effect of triptolide on secretion of inflammatory cellular factors TNF-alpha and IL-8 in peritoneal macrophages of mice activated by lipopolysaccharide, World J Emerg Med 2010; 1: 70-74.

10. Jiang $N$, Dong $X P$, Zhang SL, You QY, Jiang $X T$, Zhao $X G$. Triptolide reverses the Taxol resistance of lung adenocarcinoma by inhibiting the NF-kappaB signaling pathway and the expression of NF-kappaB-regulated drug-resistant genes, Mol Med Rep 2016; 13: 153-159.

11. Li Y, Hu S. Triptolide sensitizes liver cancer cell lines to chemotherapy in vitro and in vivo, Panminerva Med 2014; 56: 211-220.

12. Phillips PA, Dudeja V, McCarroll JA, Borja-Cacho D, Dawra RK, Grizzle WE, et al. Triptolide induces pancreatic cancer cell death via inhibition of heat shock protein 70, Cancer Res 2007; 67: 9407-9416.

13. Liu Y, Xiao E, Yuan L, Li G. Triptolide synergistically enhances antitumor activity of oxaliplatin in colon carcinoma in vitro and in vivo, DNA Cell Biol 2014; 33: 418-425.

14. Oliveira AR, Beyer G, Chugh R, Skube SJ, Majumder K, Banerjee $S$, et al. Triptolide abrogates growth of colon cancer and induces cell cycle arrest by inhibiting transcriptional activation of E2F, Lab Invest 2015; 95: 648-659.

15. Zhou J, Xi C, Wang W, Yang Y, Qiu Y, Huang Z. Autophagy plays an important role in triptolide-induced apoptosis in cardiomyocytes, Toxicol Lett 2015; 236: 168-183.

16. Festjens N, Vanden BT, Vandenabeele P. Necrosis, a well-orchestrated form of cell demise: signalling cascades, important mediators and concomitant immune response, Biochim Biophys Acta 2006; 1757: 1371-1387.

17. Hassan $M$, Watari $H$, AbuAlmaaty A, Ohba $Y$, Sakuragi $N$. Apoptosis and molecular targeting therapy in cancer, Biomed Res Int 2014; 2014: 150845.

18. Kwegyir-Afful AK, Ramalingam S, Purushottamachar $P$, Ramamurthy VP, Njar VC. Galeterone and VNPT55 induce proteasomal degradation of $A R / A R-V 7$, induce significant apoptosis via cytochrome $c$ release and suppress growth of castration resistant prostate cancer xenografts in vivo, Oncotarget 2015; 6: 27440-27460.

19. Li P, Nijhawan D, Budihardjo I, Srinivasula SM, Ahmad $M$, Alnemri ES, et al. Cytochrome $c$ and dATPdependent formation of Apaf-1/caspase-9 complex initiates an apoptotic protease cascade, Cell 1997; 91: 479-489. 